\title{
Melanin coloration in New World orioles I: carotenoid masking and pigment dichromatism in the orchard oriole complex
}

\author{
Christopher M. Hofmann, Kevin J. McGraw, Thomas W. Cronin and Kevin E. Omland
}

C. M. Hofmann (correspondence), T. W. Cronin and K. E. Omland, Department of Biological Sciences, University of Maryland Baltimore County, Baltimore, MD 21250,USA. E-mail: chofma1@umbc.edu. - K. J. McGraw, School of Life Sciences, Arizona State University, Tempe, AZ 85287, USA.

\begin{abstract}
Carotenoids produce the brilliant red, orange, and yellow colors of many animals. However, melanin pigments can also confer some of these same hues. Because carotenoid and melanin colors are produced in different ways and may serve different signaling functions, either within or between species, it is important to establish whether one or both types of pigment are responsible for coloration. We have discovered what appears to be an evolutionary switch from carotenoid- to melanin-based color in two sexually dichromatic New World orioles. Using a combination of reflectance spectrometry and chromatographic analyses of plumage pigments, we found that the chestnut plumage of adult male orchard orioles Icterus spurius is produced predominantly by phaeomelanins. Orchard oriole feathers also contain carotenoids, which appear to be masked by the high concentration of phaeomelanins. In contrast, both carotenoids and phaeomelanins appear to contribute to color in adult male Fuertes's orioles I. fuertesi. Moreover, yellow yearling male and female plumage in both species is produced by carotenoids alone. The masking of carotenoids with phaeomelanins in orchard orioles is interesting in light of the signaling roles that carotenoids are thought to play. In addition, these plumage differences produce a unique case of age and sexual pigment dimorphism in orchard and Fuertes's orioles.
\end{abstract}

Carotenoids and melanins are two of the most commonly studied color pigments used by animals. Traditionally, the bright red to yellow ornaments found in birds, fish, lizards, and frogs have been attributed to carotenoids and achromatic black or brown elements to melanins (reviewed in Fox 1976, Olson and Owens 1998, Hill 2002). Carotenoid and melanin colors are produced through different proximate mechanisms, which have played an important role in understanding their signaling function (McGraw and Hill 2000). In particular, carotenoids cannot be synthesized by vertebrates and must be obtained from the diet, although subsequent modifications may then occur (Brush 1990, Hill 2000). Many studies have claimed that these limited or costly carotenoids may reflect condition and can be used by females (or males) to evaluate the quality of a potential mate (e.g., Hill 1991, 2002, Grether 2000, Faivre et al. 2003). Melanins are synthesized from amino acid precursors (Jawor and Breitwisch 2003), and achromatic (black or brown) melanin ornaments have been demonstrated to be independent of health (McGraw and Hill 2000). Several studies have demonstrated that these melanin ornaments often serve other functions, such as signal social status (Rohwer 1975, Senar and Camerino 1998, but see Thusius et al. 2001, Tarof et al. 2005).

These differences between carotenoids and melanins have played a role in developing theories of color signaling and in some cases may also play a role in how behavioral experiments are designed. However, several recent studies have found that melanins produce some of the chestnut, orange and yellow colors that were previously attributed in whole or part to carotenoids, including the orange cheeks of the zebra finch Taeniopygia guttata (McGraw et al. 2003a), the chestnut of European and American barn swallows Hirundo rustica rustica and H. r. erythrogaster (McGraw et al. 2004a, b), and the yellow portion of red-winged blackbird Agelaius phoeniceus epaulets (McGraw et al. 2004c). Although it has been known that melanins could produce yellow, 
orange and rust colors for several decades (Fox 1976), within passerine birds it was often assumed that yellow, orange, and red colors were produced by carotenoids until recently (Johnson and Lanyon 2000, Omland and Lanyon 2000, also see discussions in Brush 1990, McGraw et al. 2004a, b, c). These brighter melanin colors are often produced by phaeomelanins, rather than eumelanins, and indicate that such generalizations about color may be overly simplified.

New World orioles Icterus also have colorful plumage that may be due to melanins. Most orioles have bright yellow or orange coloration. Biochemical analysis of the orange plumage of Baltimore orioles Icterus galbula revealed a mixture of several carotenoids (Hudon 1991), and other studies have considered orioles as having carotenoid plumage (Gray 1996, Omland and Lanyon 2000). However, adult male orchard orioles I. spurius have chestnut-colored plumage and adult male Fuertes's orioles I. fuertesi, their sister species (Clements 2000, Baker et al. 2003), have an ochre or tan color (Howell and Webb 1995, Jaramillo and Burke 1999, Baker et al. 2003), suggesting that color in these two orioles may at least in part be due to melanins rather than carotenoids. Orchard and Fuertes's orioles are sexually dichromatic, and females of both taxa have lemon-yellow plumage (see illustrations in Jaramillo and Burke 1999). Orchard and Fuertes's orioles also exhibit delayed plumage maturation, with the color of yearling males very similar to that of females (reviewed in Enstrom 1993). Even though their visual appearance suggests that female and yearling male colors are produced by carotenoids, it is possible that this plumage may also contain melanins.

The first goal of this study was to determine whether the colorful plumage of adult male orchard and Fuertes's orioles is produced by melanins, carotenoids, or both. If melanins produce the color, we wanted to determine whether they were simply replacing carotenoids or masking them. We also addressed whether females and yearling males maintain carotenoid-based plumage and represent a unique case of age and sexual pigment dimorphism.

\section{Methods}

\section{Spectral analysis}

Since several recent studies have shown that the visual appearance of plumage may be misleading (McGraw et al. 2003a, 2004a, b, c), we used both reflectance spectrometry and biochemical analysis to investigate the chemical basis of colorful plumage in orchard and Fuertes's orioles. An Ocean Optics USB 2000 portable spectrometer was used to gather reflectance spectra from both museum and field specimens. Illumination was provided by a full spectrum light source (Ocean Optics PX-2) via a bifurcated fibre optic cable that allowed for illumination and detection within the same probe. A custom matte-black anodized aluminum cylinder with a $1.27 \mathrm{~cm}$ aperture was attached to the probe and prevented ambient light from entering during measurement. We measured three different colored body regions, the breast, belly, and rump. All measurements were taken perpendicular to the surface of the body, in replicates of three, with the probe completely removed between replicates. Whenever possible, measurements were taken from nonoverlapping regions. All measurements were relative to a Spectralon diffuse white standard and corrected for dark noise. Raw spectral data were gathered into one nanometer bins, replicates were averaged, and representative spectra were generated from the five individuals measured.

Spectral measurements were taken from museum specimens at the Smithsonian National Museum of Natural History and the Delaware Museum of Natural History (Appendix 1). Five each of adult male, female, and yearling male orchard orioles were measured. Five adult male and five female Fuertes's orioles were also measured; however, we were limited to two yearling male specimens. In addition, we compared our measurements from the breast of adult male orchard oriole museum skins to measurements from living birds ( $\mathrm{n}=$ 11) captured using mist nets (see below). Field measurements and museum specimens were compared using two values derived from reflectance spectra. First, we compared the average reflectance (over 300-700 nm) from museum specimens to field measurements. Then we generated composite reflectance spectra from museum specimens and field measurements and identified the wavelength at which these two composite spectra differed the most. We then compared the reflectance of museum specimens to field measurements at this wavelength. We used a Wilcoxon-Mann-Whitney test to examine these differences between museum specimens and living birds.

\section{Biochemical analysis}

Orchard orioles were captured using mist nets and feathers were removed from the ventral surface (breast and belly) while taking standard banding measurements. All birds were given USFWS bands prior to release, which ensured that the same bird was not measured more than once (Table 1). Feathers were stored at $-20^{\circ} \mathrm{C}$ until analysis. Fuertes's oriole feathers were removed from the ventral region of 
Table 1. Concentration of carotenoid and melanin pigments in orchard and Fuertes's oriole feathers.

\begin{tabular}{|c|c|c|c|c|c|c|c|c|c|c|c|c|c|}
\hline Taxon & Sex & Age & ID no. & $\begin{array}{l}\text { Lutein } \\
\text { (ug/g) }\end{array}$ & Average & SE & $\begin{array}{l}\text { Eumelanin } \\
\quad \text { (ug/g) }\end{array}$ & Average & SE & $\begin{array}{l}\text { Phaeomelanin } \\
\text { (ug/g) }\end{array}$ & Average & SE & $\begin{array}{l}\text { Phaeomelanin: } \\
\text { carotenoid ratio }\end{array}$ \\
\hline Orchard & M & Adult & $1721-78641^{1}$ & 138 & \multirow[t]{3}{*}{125} & \multirow[t]{3}{*}{36} & 785 & \multirow[t]{3}{*}{770} & \multirow[t]{3}{*}{15} & 8550 & \multirow[t]{3}{*}{10173} & \multirow[t]{3}{*}{2037} & \multirow[t]{3}{*}{81} \\
\hline Orchard & $M$ & Adult & $1721-78639^{1}$ & 181 & & & 740 & & & 7749 & & & \\
\hline Orchard & M & Adult & $1721-78646^{1}$ & 57 & & & 785 & & & 14220 & & & \\
\hline Orchard & $M$ & Yearling & $1721-78628^{1}$ & 161 & \multirow[t]{3}{*}{313} & \multirow[t]{3}{*}{105} & 775 & \multirow[t]{3}{*}{538} & \multirow[t]{3}{*}{118} & 51 & \multirow[t]{3}{*}{59} & \multirow[t]{3}{*}{5.0} & \multirow[t]{3}{*}{0.19} \\
\hline Orchard & M & Yearling & $1721-78633^{1}$ & 265 & & & 420 & & & 68 & & & \\
\hline Orchard & $M$ & Yearling & $1721-78640^{1}$ & 513 & & & 420 & & & 59 & & & \\
\hline Orchard & $\mathrm{F}$ & & $1721-78635^{1}$ & 40 & \multirow[t]{3}{*}{113} & \multirow[t]{3}{*}{37} & 190 & \multirow[t]{3}{*}{345} & \multirow[t]{3}{*}{131} & 42 & \multirow[t]{3}{*}{38} & \multirow[t]{3}{*}{4.4} & \multirow[t]{3}{*}{0.33} \\
\hline Orchard & $\mathrm{F}$ & & $1721-78626^{1}$ & 133 & & & 605 & & & 29 & & & \\
\hline Orchard & $\mathrm{F}$ & & $1721-78638^{1}$ & 165 & & & 240 & & & 41 & & & \\
\hline Fuertes & $M$ & Adult & $\mathrm{DMNH} 44150^{2}$ & 342 & \multirow[t]{3}{*}{283} & \multirow[t]{3}{*}{48} & 1435 & \multirow[t]{3}{*}{1753} & \multirow[t]{3}{*}{199} & 623 & \multirow[t]{3}{*}{800} & \multirow[t]{3}{*}{116} & \multirow[t]{3}{*}{2.8} \\
\hline Fuertes & $M$ & Adult & $\mathrm{DMNH} 44146^{2}$ & 189 & & & 2120 & & & 761 & & & \\
\hline Fuertes & $M$ & Adult & DMNH $40009^{2}$ & 319 & & & 1705 & & & 1017 & & & \\
\hline Fuertes & $\mathrm{F}$ & & $\mathrm{DMNH} 44143^{2}$ & 5 & \multirow[t]{3}{*}{154} & \multirow[t]{3}{*}{95} & 3295 & \multirow[t]{3}{*}{2962} & \multirow[t]{3}{*}{180} & 108 & \multirow[t]{3}{*}{110} & \multirow[t]{3}{*}{26} & 0.71 \\
\hline Fuertes & $\mathrm{F}$ & & $\mathrm{DMNH} 44151^{2}$ & 126 & & & 2675 & & & 66 & & & \\
\hline Fuertes & $\mathrm{F}$ & & $\mathrm{DMNH} 44145^{2}$ & 332 & & & 2915 & & & 155 & & & \\
\hline
\end{tabular}

${ }^{1}$ USFWS band number.

${ }^{2}$ Museum voucher number. 
museum specimens at the Delaware Museum of Natural History (Table 1).

Carotenoids were extracted from 3-5 mg of feather material using the procedures of McGraw et al. (2003b). First, we separately washed feathers in $5 \mathrm{ml}$ ethanol and $5 \mathrm{ml}$ hexane for $30 \mathrm{~min}$, blotted them dry, and trimmed off the carotenoid-pigmented barbules for analysis. Colored feather portions were weighed to the nearest $0.1 \mathrm{mg}$ with an electronic balance. We then ground pigmented barbules for $15 \mathrm{~min}$ at $30 \mathrm{~Hz}$ using a Retsch MM200 mixer mill in the presence of $3 \mathrm{ml}$ methanol. Resulting mixtures were centrifuged for $5 \mathrm{~min}$ at $3000 \mathrm{rpm}$, and the supernatant was transferred to a clean tube. We evaporated the solvent to dryness under a stream of nitrogen, and the pigment residue was resuspended in $200 \mu \mathrm{l}$ of HPLC mobile phase (methanol:acetonitrile:dichloromethane, 50:46:4) prior to analysis.

HPLC analysis was performed following the methods of McGraw et al. (2004b). We injected $50 \mu \mathrm{l}$ of each sample into a Waters Alliance 2695 HPLC system fitted with a Develosil RPAqueous RP-30 column $(250 \times 4.6 \mathrm{~mm})$ and a built-in column heater set at $30^{\circ} \mathrm{C}$. We used an isocratic system at a constant flow rate of $1.2 \mathrm{ml} \mathrm{min}^{-1}$ for $60 \mathrm{~min}$ to allow sufficient time for both xanthophylls and carotenes to elute if they were present. Data were collected from 250-600 nm using a Waters 2996 photodiode array detector. We identified pigments by comparing their respective retention times and absorbance maxima to those of authentic reference carotenoids run as external standards. Lutein (absorbance-max $=447 \mathrm{~nm}$; retention time $=7.8 \mathrm{~min}$ ) was the only carotenoid present in all feathers from both species. Lutein concentration was determined using Empower software (version 5.0) by comparing peak areas at max absorbance $(447 \mathrm{~nm})$ to an external standard curve.

We analyzed the eumelanin and phaeomelanin content of feathers following the methods of McGraw et al. (2004a). To determine eumelanin concentration, 3-5 $\mathrm{mg}$ of colored barbules were trimmed and homogenized in water $(1: 100, \mathrm{w} / \mathrm{v})$, and $400 \mu \mathrm{l}$ of the homogenate were added to $800 \mu \mathrm{l}$ of $1 \mathrm{M} \mathrm{H}_{2} \mathrm{SO}_{4}$, oxidized with $3 \% \mathrm{KMnO}_{4}$. The resulting oxidation product (pyrrole-2,3,5-tricarboxylic acid; PTCA) was analyzed via HPLC (Ito and Fujita 1985, Ito and Wakamatsu 1994). Phaeomelanins were examined by hydrolyzing $200 \mu \mathrm{l}$ feather homogenate with $500 \mu \mathrm{l}$ $57 \%$ hydriodic acid at $130^{\circ} \mathrm{C}$ in the presence of $\mathrm{H}_{3} \mathrm{PO}_{2}$ for $24 \mathrm{~h}$, and subsequently analyzing the product (4amino-3-hydroxyphenyalanine; 4-AHP) using HPLC with electrochemical detection (Wakamatsu et al. 2002). Amounts of eumelanin and phaeomelanin were obtained by multiplying the amount of PTCA and 4-AHP by conversion factors of 50 and 9, respectively (Ito and Fujita 1985, Wakamatsu and Ito 2002).

\section{Results}

\section{Spectral analysis}

As in previous studies (Endler and Théry 1996, McGraw et al. 2003c), we found no significant difference in color between museum skins and living birds. Living birds (breast, $\mathrm{n}=11$ ) had an average reflectance of $10.24 \mathrm{SE} \pm 0.48$ percent; museum specimens (breast, $\mathrm{n}=5$ ) averaged $10.12 \mathrm{SE} \pm 0.23$ percent $(\mathrm{P}>0.9)$. Although average reflectance would be likely to detect changes in brightness (i.e., due to fading), average reflectance might not be able to detect changes occurring at a localized region of the spectrum. To address this issue, we also compared field and museum specimens at $472 \mathrm{~nm}$, the wavelength at which their averaged spectra differed the greatest. At $472 \mathrm{~nm}$ the reflectance from living birds was $29.53 \mathrm{SE} \pm 1.03$ percent; the reflectance from museum specimens was $28.90 \pm$ SE 1.02 percent $(\mathrm{P}>0.6)$.

Reflectance spectra from the chestnut-colored plumage of adult male orchard orioles showed a gradual increase from short to long wavelengths (Fig. 1a). This spectral shape is characteristic of the predominantly phaeomelanin-based chestnut colors found in other birds (McGraw et al. 2004a, Safran and McGraw 2004). Melanin-like reflectance spectra were found in all colored regions that we measured in adult male orchard orioles (Fig. 1a). Yellow female and yearling male plumage had spectral characteristics of carotenoids (Fig. $1 \mathrm{~b}$ and c), including a peak in the ultraviolet region of the spectrum, a minor peak around $475 \mathrm{~nm}$, a sharp increase in reflectance between $500-550 \mathrm{~nm}$, and a plateau at longer wavelengths (Bleiweiss 2004, also see examples in MacDougall and Montgomerie 2003 Fig. 1, Mays et al. 2004 Fig. 1).

Reflectance spectra from adult male Fuertes's orioles contained spectral characteristics of carotenoids and melanins and varied slightly in shape across body regions. The reflectance spectra from the rump showed stronger characteristics of a melanin based color (Fig. 2a; McGraw et al. 2004a, Safran and McGraw 2004). In contrast, the reflectance spectra from the breast and belly had a minor peak around $475 \mathrm{~nm}$ (Fig. 2a). This peak is also found in female and yearling male Fuertes's orioles (Fig. 2b and c) and is characteristic of carotenoids such as lutein (MacDougall and Montgomerie 2003 Fig. 1, Mays et al. 2004 Fig. 1). Reflectance spectra from female and yearling male Fuertes's orioles (Fig. 2b and c) were very similar to the reflectance spectra of female and yearling male orchard orioles (Fig. 1b and c). 

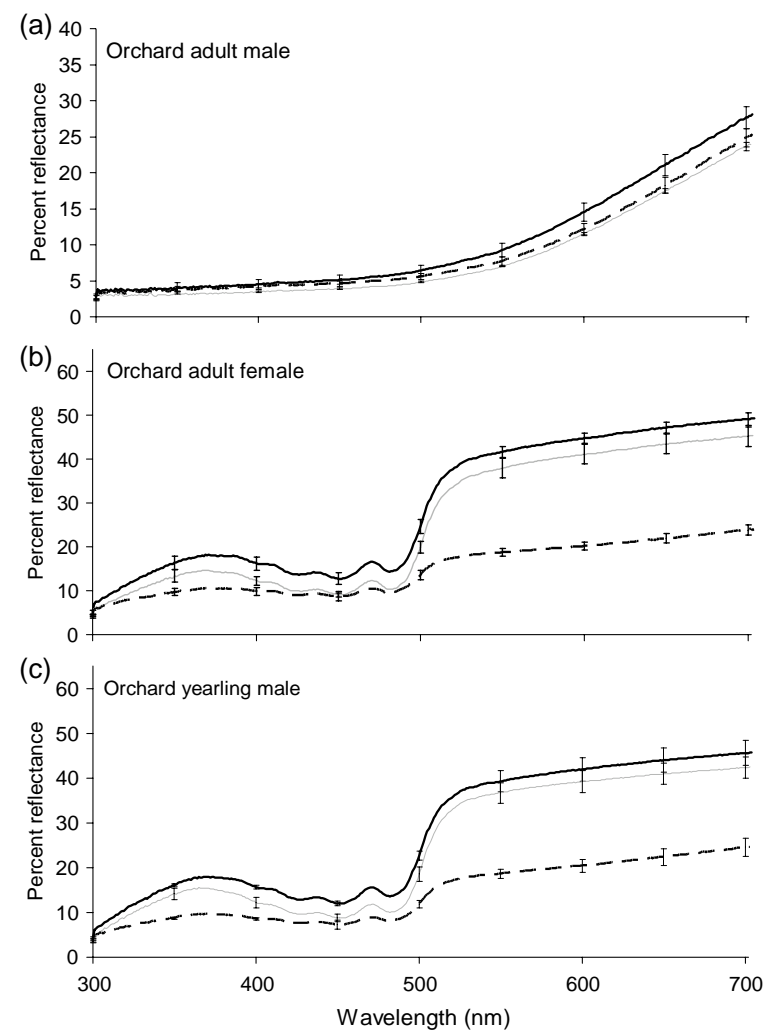

Fig. 1. Reflectance spectra of colored plumage from adult male (a), female (b), and yearling male (c) orchard orioles. Measurements were taken from belly (solid black line), breast (thin gray line), and rump (dotted black line). Spectra are averages from 5 individuals with $\pm \mathrm{SE}$ shown at $50 \mathrm{~nm}$ intervals.

\section{Biochemical analysis}

Biochemical analysis revealed that the carotenoid lutein was present in adult male, yearling male, and female orchard and Fuertes's orioles (Fig. 3, Table 1). High concentrations of melanins were found in adult male orchard and Fuertes's orioles (Fig. 3, Table 1). The chestnut colored feathers from all three adult male orchard orioles had phaeomelanin concentrations that were several orders of magnitude higher than those of yellow female and yearling male feathers (Fig. 3, Table 1). The tan feathers from adult male Fuertes's orioles had a phaeomelanin concentration that was, on average, an order of magnitude lower than that of orchard orioles. This average was still almost an order of magnitude greater than the phaeomelanin concentration of female Fuertes's orioles (Fig. 3, Table 1). Although the sample size did not permit statistical treatment of the data, the extreme differences in phaeomelanin concentration provide strong support for these differences between sex, age, and species.
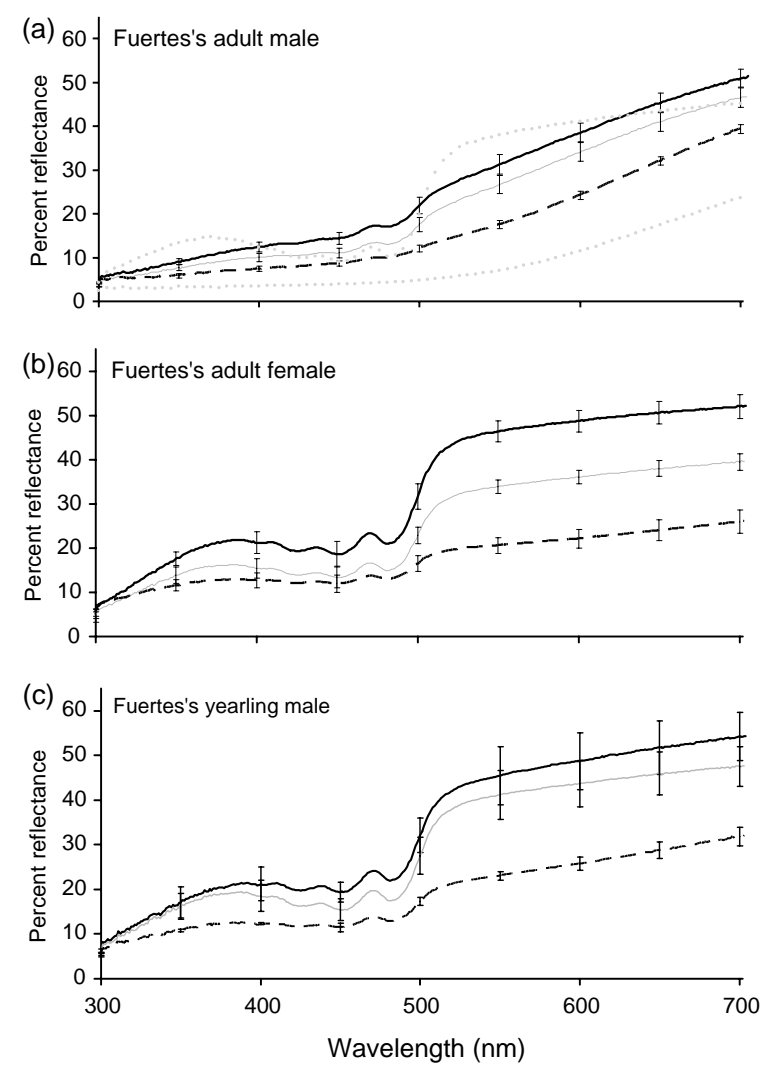

Fig. 2. Reflectance spectra of colored plumage from adult male (a), female (b), and yearling male (c) Fuertes's orioles. As in the orchard oriole (Fig. 1), measurements were taken from the belly (solid black line), breast (thin gray line), and rump (dotted black line). For comparison the male and female orchard oriole spectra are included with the adult male (dotted gray lines). Male and female spectra are averages from 5 individuals; yearling male spectra are from 2 individuals with \pm SE shown at $50 \mathrm{~nm}$ intervals.

\section{Discussion}

\section{Melanins mask carotenoids}

Our results indicate that in the chestnut-colored plumage of adult male orchard orioles, the presence of carotenoids is masked by a high concentration of melanins. These feathers do contain the carotenoid lutein; however, the high concentration of phaeomelanins effectively blocks any spectral or visual signature of carotenoids. This masking of carotenoids with a melanin-based color in adult males makes the orchard oriole unique to date. Carotenoid pigments are not found in the colorful melanin-based plumage of European and American barn swallows or eastern bluebirds Sialia sialis, which also contain high levels of phaeomelanins (McGraw et al. 2004a, b). 


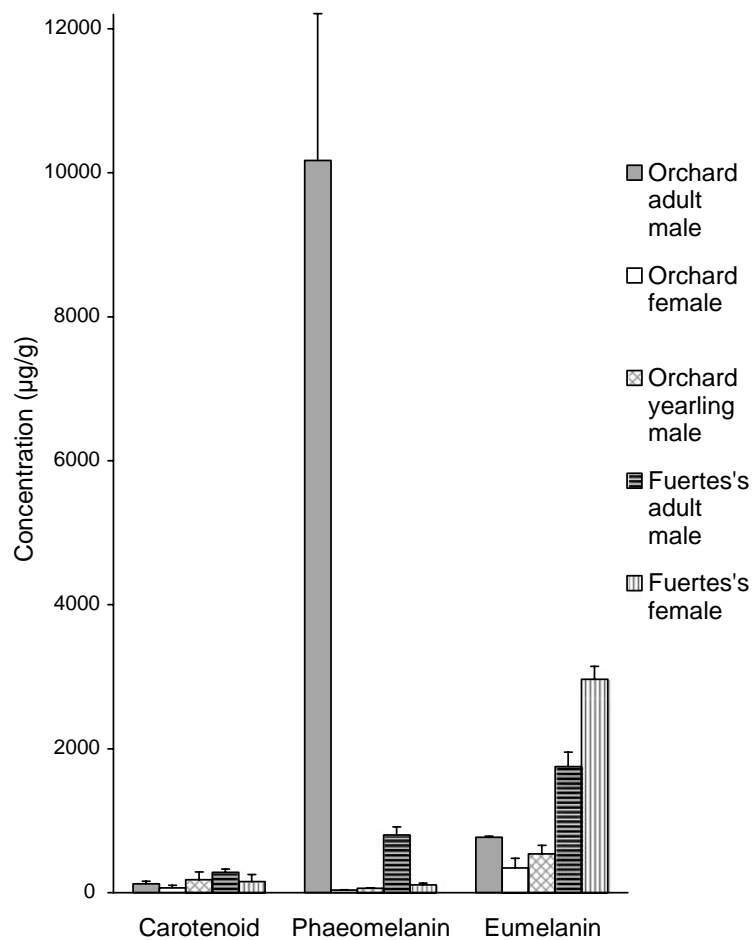

Fig. 3. The average concentration $(\mu \mathrm{g} / \mathrm{g})$ of carotenoids, eumelanins, and phaeomelanins in adult male, female, and yearling male orchard orioles, as well as adult male and female Fuertes's orioles. Only one type of carotenoid (lutein) is found, and it is present across all groups. Each bar is the average of 3 individuals $\pm S E$.

In addition, the same carotenoid pigment is present in the colorful plumage of yearling male, female, and adult male orchard and Fuertes's orioles. When yearling males molt into their full adult plumage (after second year), the observed pigment changes occur across all colored body regions. Thus orchard and Fuertes's orioles also represent a unique case of age and sexual dichromatism in which adult males have color that is produced by a different proximate mechanism.

Although we found considerable variation in carotenoid (as well as eumelanin and phaeomelanin) concentration within each age and sex class (Table 1), our results suggest that adult male orchard orioles contain levels of carotenoid pigments that are comparable to those found in females. This suggests that the concentration of pigments found in adult males would be high enough to produce carotenoid colored plumage had they not been masked. Further studies with larger sample sizes are necessary answer additional questions, such as whether yearling male orchard and Fuertes's orioles have a significantly greater concentration of lutein than females or adult males.
Why trade a carotenoid signal for a melanin one?

The masking of carotenoid-based plumage is interesting in light of the signaling roles that carotenoid colors play across a wide range of organisms. While we recognize that experimental studies demonstrating the conditiondependent and sexually selected nature of carotenoidbased plumage have yet to be performed in orioles, extending the signaling implications from numerous other passerines to orioles raises many exciting questions. If carotenoids are such honest and/or costly signals in all animals, then why would they be masked in orchard orioles? Why does this masking only occur in adult males, who are likely to be under the strongest sexual selection? Also, why do females and yearling males continue to express this putatively costly honest signal? Finally, why do Fuertes's orioles use a combination of both carotenoid and melanin pigments to produce a unique color? More research is needed in this genus and other taxa to understand the causes of such interspecific differences in elaborate colors and patterns.

\section{Relationship between pigment concentration and spectral shape}

In the adult male orchard oriole all spectral and visual characteristics of carotenoids appeared to be masked by melanins. These results suggest that carotenoids are not contributing to the visual signal in adult male orchard orioles. The only way to confirm that carotenoids were still present was through biochemical analysis. This masking appeared to be due to the high concentration of phaeomelanins found in orchard oriole plumage. In the Fuertes's oriole a lower concentration of phaeomelanins, combined with carotenoids, produced plumage with an ochre or tan color and a distinct spectral shape with characteristics of both pigments (Fig. 2a). Thus, the masking of carotenoids only occurs when high concentrations of phaeomelanins are present, and as the concentration decreases the spectral signature of carotenoids begins to reappear. Surprisingly, a high concentration of eumelanins was found in female Fuertes's orioles with little change in the reflectance spectra (Figs. 3 and 2b). Therefore, both plumage color and spectral shape appear to be largely dependent upon the concentration of phaeomelanins and the phaeomelanin:carotenoid ratio (Table 1). Future experiments investigating the effect that the selective removal of carotenoid and melanin pigments (from both adult male Fuertes's and orchard orioles) has on the reflectance spectrum presents and intriguing avenue for future research and will provide further insight into how each pigment contributes to the color signal. 
Fuertes's orioles differ from orchard orioles (and most other birds studied to date) because they use a combination of carotenoids and phaeomelanins to generate an intermediate spectral shape. Fuertes's oriole plumage differs from the olive plumage found in other birds, including adult male orioles (e.g., $I$. graduacauda), which appears to be due to mixture of carotenoids and eumelanins (Lucas and Stettenheim 1972). Plumage perceived as olive by the human eye is measured spectrally as an unsaturated yellow. The reflectance plateau of olive plumage occurs at much lower values than yellow carotenoid plumage; however, unlike the intermediate spectral shape of the Fuertes's oriole, no changes in the overall shape or location of the reflectance spectrum occur (C. Hofmann pers. obs.). Thus, orchard and Fuertes's orioles provide interesting insight into how various concentrations of carotenoids and phaeomelanins may be combined to produce unique colors with distinct spectral shapes. The co-deposition of carotenoids and melanins found in orchard and Fuertes's orioles also suggests that the signaling functions of carotenoid and melanin colors may be more complex than previously thought (i.e., a carotenoid/melanin dichotomy may be overly simplified) and both pigments may be used to produce unique colors, potentially with novel or joint signaling functions. In addition to the fact that melanins may produce bright, colorful plumage, McGraw et al. (2004c) found co-deposition of carotenoids and melanins (without the masking of carotenoids) in red-winged blackbird epaulets. Co-deposition also appears to occur convergently in Widowbird (Euplectes) epaulets and collars (K. McGraw unpubl. data). Further biochemical studies are necessary to determine whether examples of carotenoid and melanin co-deposition are widespread or only occur in a handful of taxa.

In summary, using a combination of spectral and biochemical analyses, we found that in adult male orchard orioles a carotenoid-based color is masked by a melanin-based color. In the Fuertes's oriole a combination of the two pigments produces a unique type of plumage coloration. Sexual and age dichromatism is also unique in these two orioles since both female and yearling male orchard and Fuertes's orioles have carotenoid-based coloration. The masking of carotenoids with a melanin-based color in orchard orioles is interesting in light of the very different signaling roles that carotenoids and melanins are thought to play in many other organisms as well as the supposed costs associated with producing carotenoid based colors.
Acknowledgements - We would like to thank the curators of the Smithsonian National Museum of Natural History and the Delaware Museum of Natural History for access to their collections for feather samples. Ian Tracy and Elizabeth Humphries both assisted with data collection. Trevor Price and two anonymous reviewers provided thoughtful comments. The Omland lab is a member of the Smithsonian Ornithology group. This research was supported in part by NSF grants to Kevin Omland (DEB-0347083) and to Thomas Cronin (IBN-0235820).

\section{References}

Baker, J. M., López-Medrano, E., Navarro-Sigüenza, A. G., Rojas-Soto, O. R. and Omland, K. E. 2003. Recent speciation in the orchard oriole group: divergence of Icterus spurius spurius and Icterus spurius fuertesi. - Auk 120: $848-859$.

Bleiweiss, R. 2004. Novel chromatic and structural biomarkers of diet in carotenoid-bearing plumage. - Proc. R. Soc. B 271: 2327-2335.

Brush, A. H. 1990. Metabolism of carotenoid pigments in birds. - FASEB J 4: 2969-2977.

Clements, J. F. 2000. Birds of the world: a checklist. - Ibis Publishing.

Endler, J. A. and Théry, M. 1996. Interacting effects of lek placement, display behavior, ambient light, and color patterns in three Neotropical forest-dwelling birds. - Am. Nat. 148: 421-452.

Enstrom, D. A. 1993. Female choice for age-specific plumage in the orchard oriole: implications of delayed plumage maturation. - Anim. Behav. 45: 435-442.

Faivre, B., Gregoire, A., Preault, M., Cezilly, F. and Sorci, G. 2003. Immune activation rapidly mirrored in a secondary sexual trait. - Science 300: 103.

Fox, D. L. 1976. Animal biochromes and structural colors. - Univ. of California Press.

Gray, D. A. 1996. Carotenoids and sexual dichromatism in North American passerine birds. - Am. Nat. 148: 453480.

Grether, G. Y. 2000. Carotenoid limitation and mate preference evolution: a test of the indicator hypothesis in guppies (Poecilia reticulata). - Evolution 54: 17121724.

Hill, G. E. 1991. Plumage coloration is a sexually selected indicator of male quality. - Nature 350: 337-339.

Hill, G. E. 2000. Energetic constraints on expression of carotenoid-based plumage coloration. - J. Avian Biol. 31: 559-566.

Hill, G. E. 2002. A red bird in a brown bag: the function and evolution of colorful plumage in the house finch - Oxford University Press.

Howell, S. N. G. and Webb, S. 1995. A guide to the birds of Mexico and northern Central America. - Oxford University Press.

Hudon, J. 1991. Unusual carotenoid use by the western tanager (Piranga ludoviciana) and its evolutionary implications. - Can. J. Zool. 69: 2311-2320. 
Ito, S. and Fujita, K. 1985. Microanalysis of eumelanin and phaeomelanin in hair and melanomas by chemical degradation and liquid chromatography. - Anal. Biochem. 144: 527-536.

Ito, S. and Wakamatsu, K. 1994. An improved modification of permanganate oxidation that gives constant yield of pyrrole-2,3,5-tricarboxylic acid. - Pigment Cell Res. 7: $141-144$.

Jaramillo, A. and Burke, P. 1999. New World blackbirds - Princeton Univ. Press.

Jawor, J. M. and Breitwisch, R. 2003. Melanin ornaments, honesty, and sexual selection. - Auk 120: 249-265.

Johnson, K. P. and Lanyon, S. M. 2000. Evolutionary changes in color patches of blackbirds are associated with marsh nesting. - Behav. Ecol. 11: 515-519.

Lucas, A. M. and Stettenheim, P. R. 1972. Avian anatomy. Integument. - U.S. Department of Agriculture Handbook, Washington, D.C.

MacDougall, A. K. and Montgomerie, R. 2003. Assortative mating by carotenoid-based plumage colour: a quality indicator in American goldfinches, Carduelis tristis. - Naturwiss. 90: 464-467.

Mays, H. L. J., McGraw, K. J., Ritchison, G., Cooper, S., Rush, V. and Parker, R. S. 2004. Sexual dichromatism in the yellow-breasted chat Icteria virens: spectrophotometric analysis and biochemical basis. - J. Avian Biol. 35: $125-134$.

McGraw, K. J., Gregory, A. J., Parker, R. S. and AdkinsRegan, E. 2003a. Diet, plasma carotenoids, and sexual coloration in the zebra finch (Taeniopygia guttata). - Auk 12: $400-410$.

McGraw, K. J., Beebee, M. D., Hill, G. E. and Parker, R. S. 2003b. Lutein-based plumage coloration in songbirds is a consequence of selective pigment incorporation into feathers. - Comp. Biochem. Physiol. B 135: 689-696.

McGraw, K. J., Hill, G. E. and Parker, R. S. 2003 c. Carotenoid pigments in a mutant cardinal: implications for the genetic and enzymatic control mechanisms of carotenoid metabolism in birds. - Condor 105: 587-592.

McGraw, K. J. and Hill, G. E. 2000. Differential effects of endoparasitism on the expression of carotenoid- and melanin-based ornamental coloration. - Proc. R. Soc. B 267: $1525-1531$.
McGraw, K. J., Safran, R. J., Evans, M. R. and Wakamatsu, K. 2004a. European barn swallows use melanin pigments to color their feathers brown. - Behav. Ecol. 15: $889-891$.

McGraw, K. J., Wakamatsu, K., Ito, S., Nolan, P. M., Jouventin, P., Dobson, F. S., Austic, R. E., Safran, R. J., Siefferman, L. M., Hill, G. E. and Parker, R. S. $2004 \mathrm{~b}$. You can't judge a pigment by its color: carotenoid and melanin content of yellow and brown feathers in swallows, bluebirds, penguins, and domestic chickens. - Condor 106: 390-395.

McGraw, K. J., Wakamatsu, K., Clark, A. B. and Yasukawa, K. 2004c. Red-winged blackbirds Agelaius phoeniceus use carotenoid and melanin pigments to color their epaulets. - J. Avian Biol. 35: 543-550.

Olson, V. A. and Owens, I. P. F. 1998. Costly sexual signals: are carotenoids rare, risky or required. - Trends Ecol. Evol. 13: 510-514.

Omland, K. E. and Lanyon, S. M. 2000. Reconstructing plumage evolution in orioles (Icterus): repeated convergence and reversal in patterns. - Evolution 54: 21192133.

Rohwer, S. 1975. The social significance of avian winter plumage variability. - Evolution 29: 593-610.

Safran, R. J. and McGraw, K. J. 2004. Plumage coloration, not length or symmetry of tail-streamers, is a sexually selected trait in North American barn swallows. - Behav. Ecol. 15: 455-461.

Senar, J. C. and Camerino, M. 1998. Status signaling and the ability to recognize dominants: an experiment with siskins (Carduelis spinus). - Proc. R. Soc. B 265: 1515-1520.

Tarof, S. A., Dunn, P. O. and Whittingham, L. A. 2005. Dual functions of a melanin-based ornament in the common yellowthroat. - Proc. R. Soc. B 272: $1121-1127$.

Thusius, K., Peterson, K., Dunn, P. O. and Whittingham, L. A. 2001. Male mask size is correlated with mating success in common yellowthroats. - Anim. Behav. 62: 435-446.

Wakamatsu, K. and Ito, S. 2002. Advanced chemical methods in melanin determination. - Pigment Cell Res. 15: $174-183$.

Wakamatsu, K., Ito, S. and Rees, J. L. 2002. The usefulness of 4-amino-3-hydroxyphenylalanine as a specific marker of phaeomelanin. - Pigment Cell Res. 15: 225-232. 
Appendix 1. Museum voucher numbers of orioles measured in this study.

\begin{tabular}{llll}
\hline Species & Sex & Age & Voucher no. \\
\hline Orchard oriole & M & Adult & SMNH593366 \\
Orchard oriole & M & Adult & SMNH593363 \\
Orchard oriole & M & Adult & SMNH565182 \\
Orchard oriole & M & Adult & SMNH422083 \\
Orchard oriole & M & Adult & SMNH394401 \\
Orchard oriole & M & Yearling & SMNH609478 \\
Orchard oriole & M & Yearling & SMNH362719 \\
Orchard oriole & M & Yearling & SMNH593365 \\
Orchard oriole & M & Yearling & SMNH564227 \\
Orchard oriole & M & Yearling & SMNH597265 \\
Orchard oriole & F & & SMNH341292 \\
Orchard oriole & F & & SMNH593367 \\
Orchard oriole & F & & SMNH597587 \\
Orchard oriole & F & & SMNH564228 \\
Orchard oriole & F & & SMNH597549 \\
Fuertes's oriole & M & Adult & DMNH44149 \\
Fuertes's oriole & M & Adult & DMNH44150* \\
Fuertes's oriole & M & Adult & DMNH44147 \\
Fuertes's oriole & M & Adult & DMNH44146* \\
Fuertes's oriole & M & Adult & DMNH40009* \\
Fuertes's oriole & M & Yearling & DMNH44138 \\
Fuertes's oriole & M & Yearling & DMNH360293 \\
Fuertes's oriole & F & & DMNH44145* \\
Fuertes's oriole & F & & DMNH44151* \\
Fuertes's oriole & F & & DMNH44143* \\
Fuertes's oriole & F & & DMNH44138 \\
Fuertes's oriole & F & & DMNH360293 \\
\hline & & & \\
\hline
\end{tabular}

*Indicates specimen from which feathers were analyzed. 